\title{
ESEM ANALYSIS OF ENAMEL SURFACE MORPHOLOGY ETCHED WITH ER,CR:YSGG LASER AND PHOSPHORIC ACID: IN VITRO STUDY
}

\author{
Sahar Abd El Halim*, Rasha Raafat** and Amr ElGanzory***
}

\begin{abstract}
Objectives: The aim of the present study was to evaluate the etching pattern of Er,Cr:YSGG and conventional etching on prepared samples of human enamel by environmental scanning electron microscope (ESEM).

Materials and Methods: Forty five freshly extracted human upper premolars were used; the teeth had been extracted for orthodontic reasons and were collected and stored in a solution of $0.1 \%$ (wt/vol) thymol. The teeth were mounted vertically in a self-cure acrylic cylinder. One clinician prepared all the teeth, in each tooth, a $4 \times 4 \mathrm{~mm}$ area was treated in middle third of the buccal surface. The teeth were divided into three groups according to type of etching techniques ( $n=15)$. Group(A): enamel etched with $37 \%$ phosphoric acid for $30 \mathrm{~s}$, thoroughly rinsed with distilled water for $60 \mathrm{~s}$ and gently air dried.; Group (B): enamel was irradiated with Er,Cr:YSGG laser ablated with an energy output of 4.5 watt/30hz and Group (C):enamel was irradiated with Er,Cr:YSGG laser ablated with an energy output of 4.5 watt/20hz. In group b \& c Er,Cr:YSGG laser (2.78 $\mu$ m wavelength) used for $15 \mathrm{sec}$ at 45 degree angulations working distance $5 \mathrm{~mm}$ on a square size $4 \mathrm{x} 4 \mathrm{~mm}$ on buccal surface. Micro-morphological changes of enamel surface were evaluated using an environmental scanning electron microscope at X250 \& X1500 magnification.
\end{abstract}

Results: In this study, laser with $30 \mathrm{~Hz}$ reveals a definite change in the surface of the enamel, most of the enamel prisms are interrupted showing an irregular outline. However laser with $20 \mathrm{~Hz}$ showed the ultra-structural appearance of enamel nearly similar to that of conventionally etched enamel with 37 percent phosphoric acid.

Conclusion: Within the limits of this in vitro study, both conventional acid etching \& laser 20 $\mathrm{Hz}$ etching showed nearly similar effect on enamel surface, so the laser-etching can be successfully used as an alternative to the conventional acid-etch. On the other hand laser $30 \mathrm{~Hz}$ etching failed to induce an effect on enamel surface comparable to that of acid etching and therefore can't be used as substitute for the conventional acid -etch.

\footnotetext{
* Assistant Professor, Operative Dentistry Department, Misr University for Science and Technology, Egypt.

**Lecturer of Conservative Dentistry, Faculty of Dentistry, Cairo University, Egypt.

***DDS,American Board of Prothodontics, Chicago ILL. Master of laser Since
} 


\section{INTRODUCTION}

Enamel etching is an important step during composite restorative procedures. Experimental and clinical evidence suggest that failure in maintaining resin restoration marginal integrity could ultimately lead to: marginal microleakage ${ }^{(1,2)}$, marginal discoloration ${ }^{(3)}$ and pulpal inflammatory response ${ }^{(4,5)}$. Therefore, the development of new techniques to increase the bond strength between the dental surface and the adhesive/composite resin systems (e.g. mechanical adhesion) may have profound therapeutic implications in dentistry. Among the various techniques currently in use to promote dental surface conditioning ${ }^{(6)}$, high-output lasers, such as Er:YAG laser, have been studied as an alternative method to selectively remove oral mineralized tissues for restorative purposes ${ }^{(7,8,9)}$. The therapy was based on the observation that a laser conditioned enamel surface has a modified calcium to phosphorus and carbonate to phosphorus ratio ${ }^{[10,11,12]}$. The percentage of water and organic substances is reduced ${ }^{[13]}$ which leads to a less acid-soluble and therefore more caries resistant enamel surface ${ }^{[1,12]}$. Also laser conditioning might promote the formation of micro-spaces which in turn remineralize by trapping free ions and increase caries resistance ${ }^{[13]}$. The aim of the present study was to evaluate the etching pattern of Er,Cr:YSGG and conventional etching on prepared samples of human enamel by environmental scanning electron microscope (ESEM).

\section{MATERIALS AND METHODS}

Forty five freshly extracted human upper premolars were used; the teeth had been extracted for orthodontic reasons and were collected and stored in a solution of $0.1 \%(\mathrm{wt} / \mathrm{vol})$ thymol.

Criteria for tooth selection: Intact buccal enamel not subjected to pre-treatment with chemical agents, such as hydrogen peroxide or enamel conditioner, with no cracks from the use of extraction forceps, and with no caries.
The teeth were mounted vertically in a self-cure acrylic (Rapid Repair, Detrey Dentsply Ltd, Surrey, U.K.) cylinder. One clinician prepared all the teeth, in each tooth; a $4 \times 4 \mathrm{~mm}$ area was treated in middle third of the buccal surface.

The teeth were divided into three groups according to type of etching techniques $(n=15)$. Group(A): enamel etched with $37 \%$ phosphoric acid (3M Unitek, Monrovia, USA) for $30 \mathrm{~s}$, thoroughly rinsed with distilled water for $60 \mathrm{~s}$ and gently air dried.; Group (B): enamel was irradiated with Er,Cr:YSGG laser ablated with an energy output of 4.5 watt/30hz and Group (C):enamel was irradiated with Er,Cr:YSGG laser ablated with an energy output of 4.5 watt $/ 20 \mathrm{hz}$. In group b \& c Er,Cr:YSGG laser (2.78 $\mu \mathrm{m}$ wavelength) used for $15 \mathrm{sec}$ at 45degree angulations working distance $5 \mathrm{~mm}$ on a square size $4 \times 4 \mathrm{~mm}$ on buccal surface.

Micro-morphological changes of enamel surface were evaluated using an environmental scanning electron microscope at X250 \& X1500 magnification.

\section{RESULTS}

\section{First group $30 \mathrm{~Hz}$ :}

A definite change in the surface of the enamel was noted at low power magnification (250x) as compared to the adjacent sound enamel. However, at a higher power magnification (1500x), Most of the enamel prisms are interrupted showing an irregular outline. In some areas the enamel prism boundaries were indistinct giving an irregular surface with confluence of the prismatic and interprismatic structures. (Fig1)

\section{Second group $20 \mathrm{~Hz}$ :}

Scanning electron micrograph of group2: A definite change in the surface of the enamel was noted at low power magnification (250x) as compared to the adjacent sound enamel. The normal appearance of the enamel prisms was maintained in most areas 
(honeycomb-like structure). However, confluence of the prismatic and inter-prismatic structure was noted in some areas, giving the enamel an irregular appearnce with variable sized cracks (mag. 1500x) (Fig2)

A micro-roughened surface was observed at a low energy output level of $30 \mathrm{~Hz}$, however, the depth of the roughened areas seemed lesser as compared to the higher energy output of $20 \mathrm{~Hz}$.

\section{Third group acid etching:}

A definite change in the surface of the enamel was noted at low power magnification (250x) as compared to the adjacent sound enamel. There is loss of normal enamel architecture, with parts showing micro-porosities and surface irregularities (honeycomb-like structure) mag. 1500x (Fig3). A pronounced loss of enamel substance, predominantly in the areas of prism centers with simultaneous conversion of the margin was obvious, with peripheral micro-cleft formation. Deep furrows and globular debris were also noted.

The ultra-structural appearance of enamel lased at $20 \mathrm{hz}$ was nearly similar to that of conventionally etched enamel with 37 percent phosphoric acid.

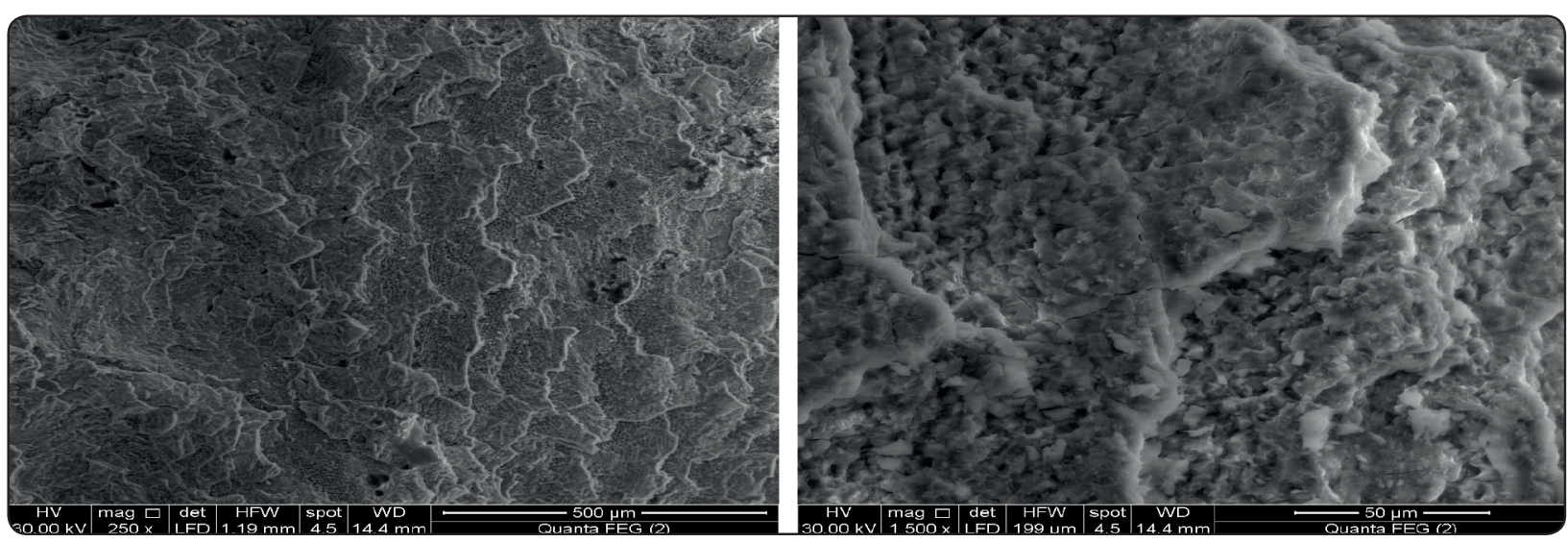

Fig. (1) Low-power magnification (250 x) and High-power magnification (1500 x) image of enamel surface lased for $30 \mathrm{~Hz}$

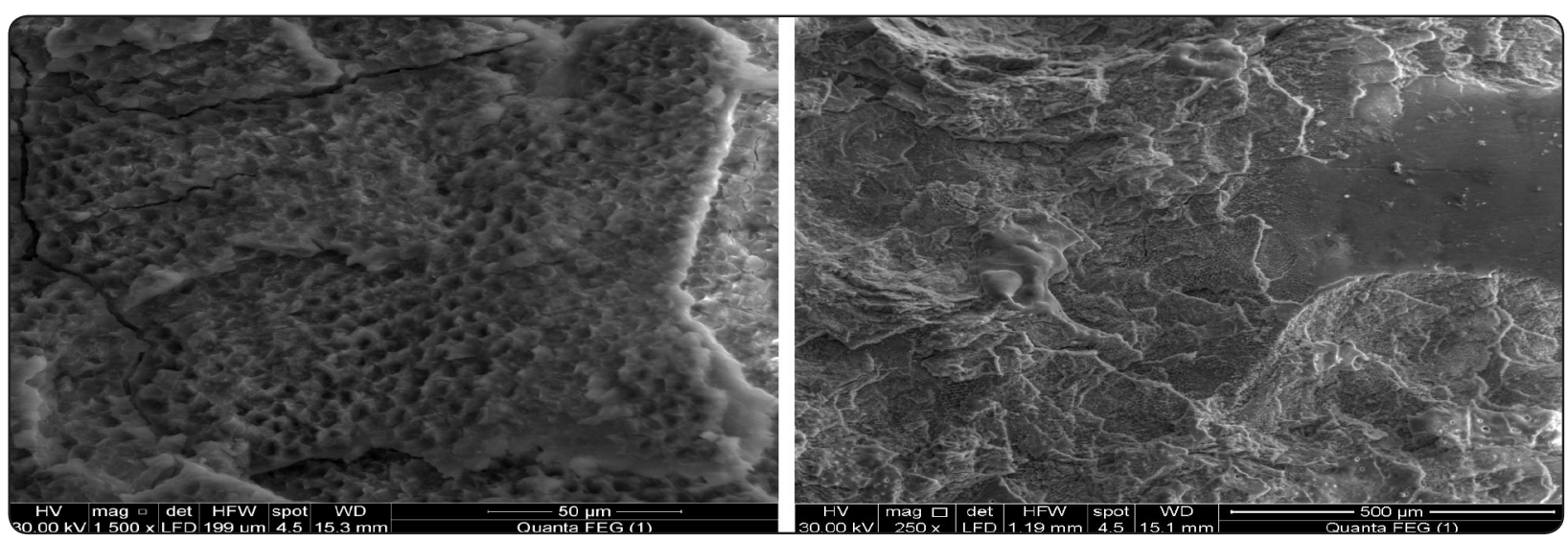

Fig.(2) Low-power magnification (250 x) and High-power magnification (1500 x) image of enamel surface lased for $20 \mathrm{~Hz}$ 

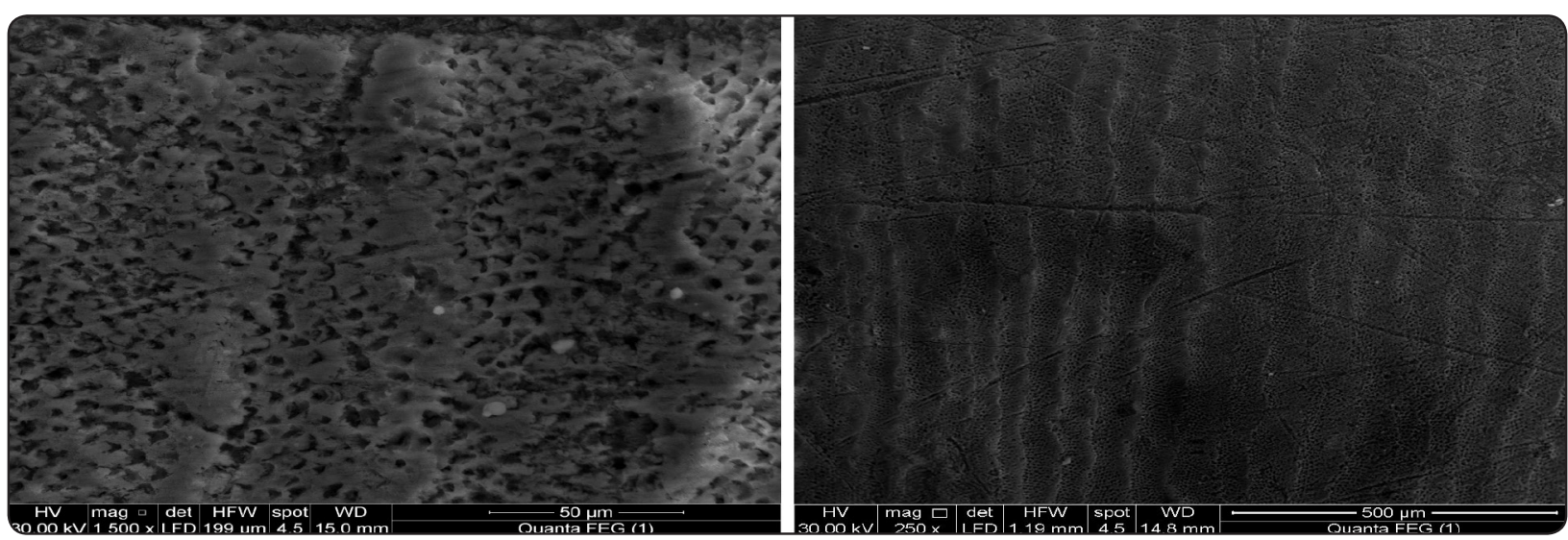

Fig.(2) Low-power magnification (250 x) and High-power magnification (1500 x) image of enamel surface lased for $20 \mathrm{~Hz}$

\section{DISCUSSION}

Currently, laser etching of enamel surfaces is popular because of the potential disadvantages of acid etching. Acid etching results in chemical changes that can modify the organic matter and decalcify the organic component. As a result of this demineralization, enamel becomes more susceptible to caries attack, which is induced by plaque accumulation around the bonded composite resin. ${ }^{[14]}$

Recently, Er:YAG and Er; Cr:YSGG lasers were introduced in dentistry. For physical and medical reasons, they are used for the treatment of hard tissue. The advantage of an Er wave is that it is well-absorbed by water and dental hard tissue. The strong absorption of water reduces the level of heat during tooth preparation. As water absorbs laser radiation better than dental hard tissue, it reduces the increasing temperature of the tissue during the preparation. Water reaches the boiling point and causes micro-explosion of the tooth. This action breaks up the surrounding tissue into small pieces and dissipates them at the same time. As this explosion occurs in water, it is so-called a preparation induced by water. Although most radiation is absorbed in water, a certain amount of heat transmission is unavoidable. Therefore, a water spray is used for cooling. This laser can also be used for etching of enamel surfaces..$^{[14,15]}$

The current study evaluate the etching pattern of Er,Cr:YSGG and conventional etching on prepared samples of human enamel by environmental scanning electron microscope (ESEM).

As a possible alternative to acid conditioning the use of laser therapy has recently shown a promising front ${ }^{[16]}$. Er,Cr:YSGG (Erbium, Chromium: Ytrium Scandium Gallium Garnet) laser, a hydrokinetic laser system having a wavelength of $2780 \mathrm{~nm}$ was investigated by Usumez et al., and was found to have ablating effect on enamel ${ }^{[17]}$

Er,Cr:YSGG laser system creates precise hard tissue cuts by the virtue of laser energy interacting with water at the tissue interface, called a hydrokinetic system. The average power output can vary from 0.1 to $8 \mathrm{~W}$. For cutting enamel high irradiation outputs 2.5 to $6 \mathrm{~W}$ can be used. ${ }^{[18]}$

In this study, laser with $30 \mathrm{~Hz}$ regards a definite change in the surface of the enamel. It was noted at low power magnification as compared to the adjacent sound enamel. However, at a higher power magnification, Most of the enamel prisms are interrupted showing an irregular outline. In some areas the enamel prism boundaries were indistinct giving a confluent irregular surface. However laser 
with $20 \mathrm{~Hz}$ showed, confluence of the prismatic and inter-prismatic structure was noted in some areas, giving the enamel an irregular appearance with variable sized cracks (mag. 1500x).

Moreover laser with $20 \mathrm{~Hz}$ showed the ultrastructural appearance of enamel nearly similar to that of conventionally etched enamel with 37 percent phosphoric acid.

This finding is in agreement with other studied that showed that Issar et al., the predominant enamel etching pattern after laser etching seen was Type III as compared to the Type I in case of acid etching. Lin et al., using Er:YAG observed the same etching pattern ${ }^{[19]}$. However in a study by Patricia et al., typical honey comb pattern of etching (type I) was observed after irradiation by Er laser ${ }^{[20]}$.

Olivi et al.,the laser system analysed was found to be effective in removing human dental enamel ${ }^{[21]}$, also Yildirim et al., the effects of $\mathrm{Er}, \mathrm{Cr}$ : YSGG laser irradiation on bond strength of self-etch adhesive to enamel depend on laser pulse frequency and the test being used ${ }^{[22]}$. Lorenz reported that the ER,Cr:YSGG laser at $2 \mathrm{~W}\left(5.6 \mathrm{~J} / \mathrm{cm}^{2}\right)$ a pattern similar to the type III acid etching pattern was described, they concluded that surface roughness after laser irradiation is reported to be similar or lower than with conventional etching ${ }^{[23]}$

However Emine et al., reported that enamel surface etching obtained with Er,Cr:YSGG laser (operated at $1.5 \mathrm{~W}$ and $1.75 \mathrm{~W}$ for $15 \mathrm{~s}$ ) is comparable to that obtained with acid etching ${ }^{[24]}$.

On the other hand, surface cracking was also evident in studies conducted by Usumez et al., Lee et al., Tachibana et al., ${ }^{[17,25,26]}$. As lower power setting was used in a study by Torun Ozer et al., no cracks were reported in their study ${ }^{[27]}$. A study by Lin et al., showed that occasional cracks enhances retention and is ideal for resin penetration ${ }^{[28]}$.

In this study, laser with $20 \mathrm{~Hz}$ regards the ultrastructural appearance of enamel nearly similar to that of conventionally etched enamel which were not present with $30 \mathrm{~Hz}$, this in agreement with studied by Uşümez et al.,Verma et al., Mizutani et al. ${ }^{[17,29,30]}$.

Moreover, another study reported that Er.Cr. YSGG laser etching was found to be more practical and faster than conventional acid etching ${ }^{[18]}$. Many factors related to this result, Er, Cr: YSGG laser enamel underwent physical changes including melting and re-crystallization, thus forming numerous pores and small bubble-like inclusions. These lasers produce super rough and micro cavitated surfaces and etches due to the vaporization of the water trapped within the hydroxyapatite matrix. It causes surface roughening and irregularity similar to that of acid etching to a depth of 10 to 20 um, depending on the type of laser and the energy applied to the surface. ${ }^{[31]}$

Thukral reported that ESEM analysis of enamel surface after Er.Cr.YSGG Laser irradiation showed the roughened enamel surfaces with intact morphology of the enamel prisms and complete absence of smear layer, so Laser-etching can be successfully used as an alternative to the conventional acid-etch. Skipping the step of acidetching also helps save chair-side time and the results of the laser etched tooth surface are superior or at least comparable to that of an acid etched tooth surface ${ }^{[32]}$.

Laser etching might be an alternative to acid etching because water and organic components are removed, reducing the risk of secondary caries. It is well known that physicochemical changes occurring after laser etching made the tooth more resistant to acid attacks and caries in the long term. Moreover, this caries reduction phenomenon was related to the changes in the calcium-to phosphorous ratio, resulting in a reduction of carbonate and pyrophosphate formation. It was also reported that remineralization spaces acting like free-ion traps occurred with laser etching ${ }^{[33]}$. 


\section{CONCLUSIONS}

Within the limits of this in vitro study it can be concluded that both conventional acid etching \& laser $20 \mathrm{~Hz}$ etching showed nearly similar effect on enamel surface, so the laseretching can be successfully used as an alternative to the conventional acid-etch. On the other hand laser $30 \mathrm{~Hz}$ etching failed to induce an effect on enamel surface comparable to that of acid etching and therefore can't be used as substitute for the conventional acid -etch.

\section{REFERENCES}

1. Luis H. SASAKI1 .Paulo D. C. Yumi M. Ii-Sei W.Antonio B. Celso Shin-Ite T.Eduardo H. Aldo B. Tensile Bond Strength and SEM Analysis of Enamel Etched with Er:YAG Laser and Phosphoric Acid:Braz Dent J (2008) 19(1): 57-61.

2. Arami S, Shahabi S, Tabatabaie M, Chiniforush N, Morshedi E, Torabi S. Assessing microleakage of composite restorations in class $\mathrm{V}$ cavities prepared by Er:YAG laser irradiation or diamond bur. J Conserv Dent 2014;17:216-9.

3. Poskus LT, Placido E, Cardoso PE. Influence of adhesive system and placement technique on microleakage of resinbased composite restorations. J Adhes Dent 2004;6:227-232.

4. Bergenholtz G. Evidence for bacterial causation of adverse pulpal responses in resin-based dental restorations. Crit Rev Oral Biol Med 2000;11:467-480.

5. Amin Davoudi, Maryam Sanei, and Hamid Badrian. Application of Laser Irradiation for Restorative Treatments. Open Dent J. 2016; 10: 636-642.

6. Hayashi M, Wilson NH. Marginal deterioration as a predictor of failure of a posterior composite. Eur J Oral Sci2003;111:155-162.

7. Van Meerbeek B, Van Landuyt K, De Munck J, Hashimoto M, Peumans M, Lambrechts P, et al..Technique-sensitivity ofcontemporary adhesives. Dent Mater J 2005;24:1-13.

8. Kim ME, Deuk-Jin J, Kim KS. Effects of water flow on dental hard tissue ablation using Er:YAG laser. J Clin Laser Med Surg 2003;139-144.

9. Bertrand MF, Brulat N, Lazzarini V, Marcato G, Namur S, Roca JP. Er:YAG laser cavity preparation and semi-direct composite resin restoration: a microleakage study. Photom Laser Surg 2008;26 (in press).

10. Lorenz M. Brauchli. Andrea S. Christiane S. Judith B and Andrea W. Laser Conditioning of Enamel with the Erbium YAG and the CO2 Laser.Bond Strength and Surface Structure. Dentistry 2011, 1:2Volume 1 • Issue 2 •

11. Raucci-Neto W, De Castro LM, Corrêa Afonso AM, Da SilvaRS, Pécora JD, Palma-Dibb RG. Assessment of thermal alterationduring class $\mathrm{V}$ cavity preparation using the Er:YAGlaser. Photomed Laser Surg 2007;25:281-286.

12. Geraldo-Martins VR \& Lepri CP\& Palma-Dibb RG. Influence of Er,Cr:YSGG laser irradiation on enamel caries prevention Lasers. Med Sci 2013; 28:33-39

13. Lin CP, Lee BS, Lin FH, Kok SH, Lan WH. Phase, compositional, and morphological changes of human dentin afterNd:YAG laser treatment. J Endod 2001;27:389-393.

14. Santos CR. Apllication of Er:YAG and Er,Cr:YSGG lasers in cavity preparation for dental tissue: A literature review. World J Dent 2012;3:340-3.

15. Hoshing UA, Patil S, Medha A, Bandekar SD. Comparison of shear bond strength of composite resin to enamel surface with laser etching versus acid etching: An in vitro evaluation. J Conserv Dent 2014;17:320-324.

16. Parker S Introduction, history of lasers and laser light production. BDJ. 2007; 1:21-31.

17. Usumez S, Orhan M, Usumez A. Laser etching of enamel for direct bonding [3] with an Er,Cr:YSGG hydrokinetic laser system. Am J Dentofacial Orthop. 2002;122:649-56.

18. Krishnan KV, Kumaran NK, Iyer VH, Rajasigamani K. Laser Etched vs Conventional Etched Enamel : Effect on shear bond strength of orthodontic brackets. International Journal of Laser Dentistry, 2013;3(1):1-6.

19. Issar R, Mazumdar D, Ranjan S, Kumar Krishna N, Kole R, Priyankar S, LakiangD, Jayam C. Comparative Evaluation of the Etching Pattern of Er,Cr:YSGG \& Acid Etching on Extracted Human Teeth-An ESEM Analysis. Journal of Clinical and Diagnostic Research. 2016 May, Vol-10(5): ZC01-ZC05

20. Patricia T, Joao CF, Sofia AO, Alvaro FA, Walter RD, Paulo RM. Shear bond strength and SEM morphology evaluation of different dental adhesives to enamel prepared with Er:YAG laser.Contemp Cl Dent. 2013;4:20-26.

21. Olivi G, Angiero F, Benedicenti S, Iaria G, Signore A\& Kaitsas V. Use of the erbium, chromium:yttriumscandium-gallium-garnet laser on human enamel tissues. Influence of the air-water spray on the laser-tissue 
interaction: scanning electron microscope evaluations. Lasers Med Sci 2010; 25:793-797

22. Ayar MK, Yildirim T. Effects of Er,Cr:YSGG Laser Pulse Frequency on Microtensile Bond Strength to Enamel. Oper Dent. 2016 Nov 1.

23. Lorenz M. Brauchli, Andrea Schramm, Christiane Senn, Judith Ball and Andrea Wichelhaus. Laser Conditioning of Enamel with the Erbium YAG and the CO2 Laser.Bond Strength and Surface Structure. Dentistry 2011, 1:2

24. Emine G, Emrah A, Güvenç B, Köksal B. Influence of different power outputs of erbium, chromium:yttriumscandium-gallium-garnet laser and acid etching on shear bond strengths of a dual-cure resin cement to enamel. Lasers in Medical Science January 2011, Volume 26, Issue 1, pp 13-19

25. Tachibana A, Marques M, Soler J, Matos A. Er,Cr:YSGG laser for caries removal : influence on bonding of a self etching adhesive system. Lasers Med Sci. 2008; 23:435-41.

26. Lee B, Hsieh T, Lee Y. Bond strengths of orthodontic bracket after acid etched, Er:YAG laser irradiated \& combined treatment on enamel surface. The Angle Orthodontist. 2002;73:565-70.

27. Ozer T, Basara G, Berk N. Laser etching of enamel for orthodontic bonding. Am J Dentofacial Orthop. 2008; 134:193-97.
28. Lin S, Caputo A, Eversole L, Rizoiu I. Topographical characteristics and shear bond strength of tooth surfaces cut with a laser-powered hydrokinetic system. Journal of Prosthetic Dentistry. 1999; 82:451-45.

29. Verma M, Kumari P, Gupta R, Gill S, Gupta A. Comparative evaluation of surface topography of tooth prepared using erbium, chromium: Yttrium, scandium, gallium, garnet laser and bur and its clinical implications. J Indian Prosthodont Soc. 2015 Jan-Mar;15(1):23-28.

30. Mizutani K, Aoki A, Coluzzi D, Yukna R, Wang CY, Pavlic V, Izumi Y. Lasers in minimally invasive periodontal and peri-implant therapy. Periodontol 2000. 2016 Jun;71(1):185-212.

31. Vijayan V, Rajasigamani1 K, Karthik1 K, Maroli S, Chakkarayan J, Haris M. Influence of erbium, chromium-doped: Yttriumscandium-gallium-garnet laser etching and traditional etching systems on depth of resin penetration in enamel: A confocal laser scanning electron microscope study. J Pharm Bioall Sci 2015;7:S616-22.

32. Thukral S. LASERS ETCHING. Journal of Laser Dentistry Vol. 1 - Issue 1, Jan. 2007.

33. Baygin O, Korkmaz FM, Tuzuner T and Tanriver M. The Effect of Different Techniques of Enamel Etching on the Shear Bond Strengths of Fissure Sealants. Dentistry 2011, 1(3):1-5. 